\title{
A noção de transferência cultural
}

Autor: ESPAGNE, Michel ${ }^{1}$

Tradução: MAGRI, Dirceu ${ }^{2}$

\section{Resumo}

Toda passagem de um objeto cultural de um contexto para outro tem por consequência uma transformação de seu sentido, uma dinâmica de ressemantização, que só se pode reconhecer plenamente se levarmos em conta os vetores históricos da passagem. Logo, pode-se dizer que a pesquisa sobre as transferências culturais diz respeito à maioria das ciências humanas, mesmo se ela se desenvolveu a partir de uma série de pontos de ancoragem específicos. $\mathrm{O}$ estudo das transferências culturais leva a relativizar a importância da comparação e, acima de tudo, a noção de centro.

\section{Palavras-chave:}

História das ciências humanas, transferência cultural, historiografias transnacionais

\section{Keywords:}

History of human sciences, cultural transfer

Toda passagem de um objeto cultural de um contexto para outro tem por consequência uma transformação de seu sentido, uma dinâmica de ressemantização, que só se pode reconhecer plenamente se levarmos em conta os vetores históricos da passagem. Logo, pode-se dizer que a pesquisa sobre as transferências culturais diz respeito à maioria das ciências humanas, mesmo

\footnotetext{
${ }^{1}$ Ver referências final do artigo.

${ }^{2}$ Mestre e Doutor em Estudos Linguísticos, Literários e Tradutológicos em Francês, pela Universidade de São Paulo.
} 


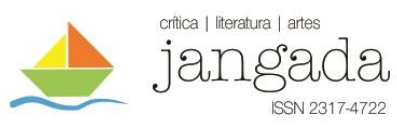

se ela se desenvolveu a partir de uma série de pontos de ancoragem específicos. Ir além dessa definição minimalista pressupõe fechar uma série de pistas falsas que parece implicar o termo em si. Transferência, não é transportar, mas sim metamorfosear, e o termo não se reduz de modo algum à questão mal circunscrita e bastante banal dos intercâmbios culturais. É menos a circulação de bens culturais que sua reinterpretação que está em jogo.

A noção de transferência cultural se desenvolveu no contexto dos estudos da Alemanha do século XIX em suas ligações com a França (ESPAGNE; WERNER) ${ }^{3}$. A referência a Alemanha detém então uma importância estrutural no desenvolvimento das ciências do homem. De Victor Cousin, que instituiu o permanente quadro da filosofia francesa, alegando suas relações com Hegel ou Schelling, até Jacques Offenbach, cuja música acompanha a celebração do segundo Império, a Alemanha tornou-se um elemento constitutivo da vida intelectual francesa. O positivismo ou o saint-simonismo não estão isentos de uma concepção que caracteriza os estudos romanos ou as ciências da Antiguidade. ${ }^{4}$

Para abordar esta referência era preciso, por um lado, perceber que o conhecimento objetivo da área cultural era menos importante do que as alterações a que ela poderia dar origem e, por outro lado, explorar os vetores da transferência. As transferências culturais se situavam desde então no ponto de encontro de uma pesquisa do tipo hermenêutica, centrada na determinação de novos sentidos, e de uma busca histórico-sociológica acerca de todos os vetores de transferências entre os dois países. Podia-se reconhecer ao mesmo tempo traços de um conhecimento de Hegel entre os simonianos, observar as reconstruções inteiramente originais, às quais tinham dado origem e acompanhar de perto a frequência às universidades prussianas por aqueles que transmitiriam elementos de saber. A pesquisa sobre a transferência cultural deveria admitir que se pode apropriar de um objeto cultural e emancipá-lo do modelo que o constitui, ou seja, uma transposição, por mais distante que ela seja, tem tanta legitimidade quanto o original. Nesse sentido, nas ciências humanas e sociais, a comparação como princípio adicional de abertura para diferentes espaços foi perdendo o seu interesse e teve que ser substituída pela observação das formas de miscigenação e hibridismo. ${ }^{5}$ Assim, pensar em termos de transferências culturais levava a relativizar a importância da comparação. Esta, na

\footnotetext{
${ }^{3}$ Veja também: http://geschichte-transnational.clio-online.net/transnat.asp

${ }^{4}$ É entre os saint-simonianos que se encontram os primeiros alunos franceses de Hegel. A referência às ciências alemãs da antiguidade na França do século XIX, deve-se, por exemplo, ao monumental esforço de tradução do Simbolismo de Creuzer, por Joseph Guigniaut (1825-1852).

${ }^{5}$ Por miscigenação covém entender a ressemantização ligada ao encontro de duas entidades culturais que, elas mesmas, resultam de encontros e de ressemantizações anteriores. Veja : Jean-Loup Amselle, Branchements, Anthropologie de l'universalité des cultures. Paris : Flammarion, 2001.
} 


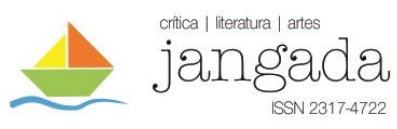

verdade tende a opor entidades para contabilizar suas semelhanças e suas diferenças, mas ela não leva em conta o observador que compara, opõe-se para juntar, projeta seu próprio sistema de categorias, cria as oposições que ele reduz e, em geral, ele mesmo pertence a um dos dois termos da comparação. Com base principalmente na gramática comparativa das línguas indoeuropeias, o comparatismo se atém aos seus limites. Parece-me particularmente delicado abordar pelo viés de uma história comparada os territórios fora da Europa e, de um modo geral, relacionar territórios, culturas ou literaturas entre as quais uma diferença qualitativa radical está implicitamente pressuposta.

Do mesmo modo, a categoria de influência, cuja etimologia é suficiente para mostrar a dimensão mágica, devia ser substituída por uma abordagem crítica de contatos historicamente verificáveis e de adaptações ou reinterpretações nas quais estes contatos tivessem ocorrido. Assim como seria oportuno a economia dos conceitos de autenticidade na transmissão ou superioridade do original sobre a cópia. Sabe-se que um discípulo secundário de Schelling, Krause, criou no mundo hispânico uma escola de pensamento, o "krausismo", que relega à sombra o resto da filosofia alemã e é baseada em um conhecimento de fundo bastante breve dos textos. O fato é que esta forma de pensamento liberal, aliás, marcando um deslize disciplinar da metafísica schellingniana a um pensar político, é tão legítima quanto o impulso que lhe deu origem. Não medimos o krausismo por seu grau de fidelidade a Schelling, assim como não julgamos a tradução de Sófocles por Hölderlin pelo grau de exatidão com que os segmentos textuais foram transpostos. Em última análise, o conhecimento de uma tradição antes da sua importação e sua reconstrução pode ser extremamente sucinto.

Todos os grupos sociais suscetíveis de passar de um espaço nacional ou linguístico étnico ou religioso a outro podem ser vetores de transferência cultural. Os comerciantes transportando mercadorias transmitiram também representações ou conhecimentos. Os tradutores, os professores especialistas em uma cultura estrangeira, emigrados políticos, econômicos ou religiosos, os artistas, respondendo a chamados, os mercenários, são todos veículos de transferências, e deve-se levar em conta suas diferentes mediações. No entanto, pode-se muito bem representar as transferências com base na circulação de objetos, como livros ou obras de arte. A história das bibliotecas, a constituição de fundos estrangeiros, a divulgação dos produtos editoriais e da tradução, como a história das coleções e do mercado transnacional da arte, obviamente fazem parte da pesquisa sobre transferências culturais. E quando passamos das mediações humanas às mediações associadas a livros ou a arquivos, a questão das transferências culturais encontra a da memória. De fato, bibliotecas ou arquivos, cujos modos 


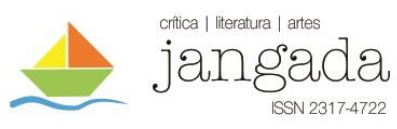

de organização muitas vezes merecem que estabeleçamos história, tendem a reforçar as identidades. Eles geralmente são organizados seguindo um princípio de relevância que corresponde às representações da identidade de um grupo, a maior parte do tempo, nacional. Tornar-se atento às transferências culturais envolve revisar, pelo menos de forma virtual, as estruturas da memória coletiva das bibliotecas e dos arquivos, à procura de itens importados, muitas vezes marginalizados. Além disso, a mobilização de um elemento de memória estrangeira não é fortuita. Quando se busca nos estratos da memória um elemento estrangeiro ao contexto de recepção, geralmente é para atender a um grupo de objetos relevantes desse mesmo contexto de recepção. Convém-se distinguir entre memória acumulada, ainda não inutilizada, e memória efetiva.

Uma transferência cultural nunca ocorre somente entre duas línguas, dois países ou duas áreas culturais: quase sempre há terceiros envolvidos. Portanto, deve-se representar antes as transferências culturais como interações complexas entre vários polos, diversas áreas linguísticas. Fazemos da passagem do Iluminismo francês na Alemanha um fenômeno muito mais próximo se negligenciarmos suas raízes inglesas e seus prolongamentos russos. E abordar a cultura da Rússia na época de Catarina II, é compreender a interação entre o Império Russo, a cultura alemã da Imperatriz, seu interesse pela França e por uma Itália muitas vezes revista através do prisma da literatura francesa. No entanto, se é fácil reconhecer os lugares onde se encontram os numerosos espaços culturais, lugares que poderíamos considerar "portais da globalização", utilizando-se de um neologismo, a descrição só se pode operar no encontro de um número limitado de termos. A representação dos cruzamentos generalizados permanece inoperante.

Mesmo quando se aborda uma transferência entre dois espaços culturais, não se pode de forma alguma considerá-los cada um como homogêneo e original: cada um é, em si, o resultado de deslocamentos anteriores; cada um tem uma história feita de sucessivas hibridações. Convém ter isso em mente quando se tenta descrever, por exemplo, uma transferência cultural francoalemã. Nem a Alemanha, nem a França são essências. No entanto, por mais discutíveis que sejam essas entidades, a necessidade de uma descrição nos obriga a supor, por um momento fugaz, a existência de um sistema que chamaremos de Alemanha ou França, helenismo ou latinidade. Mas a ênfase será imediatamente mostrar que essas entidades são elaboradas a partir das importações. A França é a Alemanha, como a latinidade é grega ou a escolástica medieval é árabe, o budismo chinês é indiano, etc. As áreas culturais, cuja pesquisa sobre as 
transferências culturais revela entrelaçamentos, são portanto configurações provisórias, mas necessárias à compreensão dos fenômenos de circulação cultural.

De um modo geral, as ciências humanas correspondem a relatos nacionais, limitados a espaços linguísticos particulares. Elas fabricam identidades a partir de importações e reformulações que as acompanham. A revisão sistemática destas construções identitárias oferece à pesquisa sobre transferências culturais um vasto campo de investigações, cujo horizonte seria uma história transnacional das ciências humanas.

Mesmo se a filosofia, a exemplo da matemática, reivindica uma universalidade de princípio, uma independência dos conceitos ante as línguas que as veiculam, parece que ela se desenvolveu ao longo do século XIX com uma referência alemã, a ideologia laica da Terceira República invocando um kantismo renovado. Naturalmente, nem o Schelling de Ravaisson ou o Hegel de Kojève correspondem aos originais cujos intérpretes reivindicam. É do maior interesse determinar o que sua interpretação acrescenta, mas deve-se sobretudo observar que uma tradição intelectual, pretendendo constituir uma moralidade cívica nacional, constrói-se a partir de referências importadas. A fenomenologia seria dificilmente concebível sem uma importação de Husserl, precedido de outras formas de circulação daquilo que se elaborou sobre o fundamento dessa referência. Nisso, a filosofia francesa não é exclusiva, e Martial Gueroult já tinha se encarregado de trazer à luz tudo o que Fichte devia a discursos da Revolução francesa, às tomadas de posições políticas expressas na França de sua época. Sem dúvida, a tendência de um segmento significativo da filosofia francesa contemporânea de exprimir em inglês uma "philosophie de l'esprit", resultando em grande parte da tradução inglesa da filosofia austríaca, corresponde ao mesmo esquema de construção de uma identidade que se pretende universal a partir de um sistema de referências de uma cultura importada, cujos conceitos centrais têm, por outro lado, ancoragens linguísticas largamente ignoradas.

Em história da arte, um modelo de transferência é fornecido tanto pela aplicação a Itália da hermenêutica alemã, que pela busca de elementos de um estrato cronologicamente anterior em um estrato posterior (transferências diacrônicas, por exemplo, a Idade Média na Renascença). Quando Heinrich Wölfflin aplica a Itália seus conceitos fundamentais de história da arte, ele não faz nada mais que transpor categorias da psicologia alemã para um outro espaço (WÖLFFLIN, 1915). Carl Justi não procede de modo muito diferente quando aplica à arte de Velázquez ou, de preferência, ao fenômeno Velázquez em sua época, categorias relacionadas à hermenêutica de Wilhelm Dilthey (JUSTI, 1903). Quando Anton Springer observa na arte medieval alemã traços da Antiguidade reinterpretados de acordo às necessidades de um novo 
contexto, ele não faz nada mais que analisar uma transferência cultural, e suas observações servirão de modelo a Aby Warburg, que o lê durante sua estadia em Florença (SPRINGER, 1867).

A antropologia enquanto ciência é particularmente atenta às relações entre culturas, seus contatos e às formas de interpenetração que lhes imprimem uma dinâmica. É bastante notável que um dos fundadores da antropologia americana, Franz Boas, alemão de Minden que emigrou para os Estados Unidos, onde aplicou ao estudo dos índios da costa oeste, sobretudo os Kwakiutl, modos de abordagem copiados das coleções de músicas dos irmãos Grimm. Tratavase de reunir histórias em língua indígena, transcrevê-las pela primeira vez antes de analisá-las, e de reconhecer o que elas revelavam sobre as sociedades indígenas. E quando estudava as contaminações entre etnias, Boas procurava observar contatos historicamente reconhecíveis para justificar as recorrências sistêmicas, as homologias estruturais. Ele não buscava comparar, mas observar a gênese de imbricações, acompanhar contaminações. Não só o percurso biográfico e intelectual de Boas é um caso notável de transferência cultural, mas o método que ele desenvolve é especialmente adaptado para este fenómeno. E não só Boas incarna de maneira suficientemente brilhante a ideia de transferência cultural na antropologia, para que uma análise cuidadosa do seu trabalho a partir desta perspectiva se imponha, mas muitos de seus discípulos próximos são imigrantes vindos da Europa germânica, participando de um vasto deslocamento para os Estados Unidos de conhecimentos adquiridos em outros lugares. Em geral, a ideia transmitida por Boas, segundo a qual a língua é o principal marcador de uma cultura, é um legado de Humboldt, cujos traços podemos seguir por toda a Europa e especialmente na Rússia onde, pela mediação do Heymann Steinthal e de alguns alunos eslavos, participa da base sobre a qual repousa o formalismo linguístico e antropológico. Quando Lévi-Strauss, que se liga a isso por meio de Jakobson, vai para a América e encontra Boas, duas formas de transferências fundamentais em antropologia se convergem.

Em literatura, o foco é sobre as traduções (que, apesar de sua presença maciça nas livrarias, ainda são consideradas como um elemento exterior, ligeiramente periférico); sobre as figuras de articulação entre as tradições literárias, sobre os panteões estrangeiros que cada cultura constrói (após Eugène-Melchior de Vogué, Tolstoy tornou-se, se não um escritor francês, pelo menos um escritor central no Panteão francês das literaturas estrangeiras), sobre os escritores usando uma língua que não é a sua (o turco de língua alemã Feridun Zaimoglou ao russo de língua francesa Andrei Makine, passando pelo somaliano de língua Somali inglesa Nuruddin Farah). Nesta perspectiva, a história literária pode ser revista do ponto de vista de 


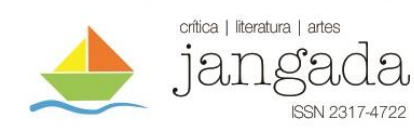

continuidades alternativas, não se levando em conta somente os elementos nacionais. Stefan George era profundamente inspirado por Mallarmé, que o traduziu, ou Hölderlin por Rousseau; não deveríamos tentar reconstruir filiações na história do lirismo na Alemanha que não levassem em conta estas contribuições externas. Mas André Chénier e Schiller seriam, pelas mesmas razões, momentos da literatura russa; e o conjunto das histórias literárias deveria, portanto, ser reescrito.

A percepção que as culturas literárias nacionais, ou maiores, têm umas das outras é determinada pelas ciências das áreas culturais próximas, por exemplo, a romanística alemã ou a eslavística francesa. Essas ciências resultam de um compromisso entre o espaço literário estudado e o horizonte próprio daquele que as observou. Além disso, elas podem ser objeto de importações. Se considerarmos, por exemplo, que a romanística alemã tal como a representava Friedrich Christian Diez é, por sua abordagem, própria de uma globalidade das culturas românicas, e marcada por uma concepção dos objetos de filologia claramente emprestada de uma tradição alemã, sua importação na França por Gaston Paris, que a aplica de modo privilegiado à Idade Média francesa, corresponde a uma reinterpretação de seu próprio objeto, a "românia".

A análise das histórias literárias sob a perspectiva das transferências culturais, em que constituem testemunho, é tanto mais significativa que, em todos os países europeus, são parte integrante da construção das nações. Desde a Chanson de Roland (A Canção de Rolando) até o Dit du prince Igor ( $O$ Dito do Príncipe Igor), não há nenhuma nação europeia que exista sem o texto fundador - encontrado em áreas longínquas (por exemplo a Histoire de Kieu na literatura vietnamita, Le Chevalier à la peau de panthère ( $O$ Cavaleiro na pele de pantera) na Geórgia e até mesmo na Antiguidade com a epopeia de Gilgamesh). Mas é evidente que estas construções são frequentemente relacionadas às importações estrangeiras. O Kalevipoeg de Kreutzvald, epopeia nacional estoniana, é o resultado do trabalho de filólogos formados em uma tradição alemã, pós-herderiana, que sentimos igualmente em ação na grande epopeia finlandesa que foi Kalevala de Lönnrot. Há marcas da poesia ossiânica na interpretação que faz Friedrich August Wolf da epopeia homérica, que é a criação de todo um povo. A partir de Ossian e Herder, o modelo de obra fundadora de uma nação se estabeleceu por toda a Europa. A revisão da história literária sob a perspectiva das transferências culturais permite destacar a circulação de modelos suscetíveis de fundar literaturas nacionais.

De fato, algumas ciências humanas transcendem de imediato os contextos nacionais. Veja-se, por exemplo, o caso do orientalismo, tal como se desenvolveu desde o início do século 


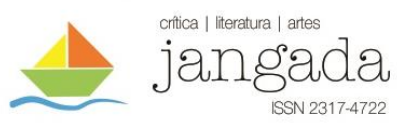

XIX: um periódico como o Journal asiatique pode então aparecer como um órgão francoalemão de exploração das literaturas e culturas do Oriente Próximo, em particular o árabe, o turco e o persa. Figura central desta nova disciplina, Silvestre de Sacy, em matéria de estudos orientais, foi também uma espécie de "praeceptor Germaniae", uma vez que a maior parte dos titulares da cadeira de estudos orientais na primeira metade do século XIX foram seus alunos. Tudo se passa como se a França e a Alemanha, às quais poderíamos facilmente acrescentar a Inglaterra, a Itália e a Rússia, abandonando a ambição de construir ciências separadas sobre o Oriente, tivessem procurado dispor de uma percepção comum, baseando-se ela mesma em um compromisso, por um lado, objeto em toda a sua complexidade e sua diversidade e, por outro lado, sua própria estrutura conceitual.

A pesquisa sobre as transferências faz parte das historiografias culturais transnacionais. Mas isso não significa que ela se reduz à análise das imbricações entre espaços nacionais da Europa moderna. Ela pode muito bem encontrar outros campos de aplicação. A apropriação por parte da corte do imperador da China das matemáticas europeias, tal como foram transmitidas pelos missionários jesuítas, para tornaram-se no Extremo Oriente um sinal de poder, corresponde plenamente a um fenômeno de transferência cultural, assim como o papel desempenhado pela Prússia na reforma da sociedade japonesa na era Meiji. Na Antiguidade, mais ainda que nos tempos modernos, é costume considerar o Império Romano ou o mundo grego como entidades homogêneas. Ora, há muito a arqueologia tem observado fenômenos de miscigenação; ela está à procura de passagens difíceis de identificar entre o Egito e Grécia, entre as matemáticas mesopotâmicas e as matemáticas gregas. Uma mudança de perspectiva poderia levar a considerar a Antiguidade clássica como um contexto de reapropriações em cadeia de elementos próprios às culturas ao redor do Mediterrâneo. Nas costas da atual Turquia, as cidades gregas eram povoadas tanto por Carianos $^{6}$, Licianos $^{7}$ ou lídios ${ }^{8}$ aculturados, e vestígios arqueológicos de cidades hititas da Anatólia mostram a presença de colônias estrangeiras mesopotâmicas. As imbricações não são unilaterais, em suma. O encontro das culturas da Antiguidade clássica com os povos situados na sua periferia também permitiu o surgimento de entidades novas, da Báctria ou da Sogdiana greco-iraniano-budista ${ }^{9}$ ligadas à cultura galo-romana.

\footnotetext{
${ }^{6}$ Homero se refere ao povo de Mileto (localizada na costa ocidental da península da Anatólia, na atual Turquia) por Carianos. - (Nota do tradutor)

${ }^{7}$ Natural da Lícia, na Anatólia, Ásia Menor. - (Nota do tradutor)

${ }^{8}$ Natural da Lídia, também na Anatólia, Ásia Menor. - (Nota do tradutor)

${ }^{9}$ Algumas línguas mortas da Ásia Central (sogdiana, tocariana) praticamentes só são comprovadas por corpus de traduções a partir de outras línguas.
} 


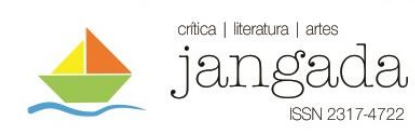

Que a história arcaica das sociedades sobre as quais se funda a autopercepção da Europa moderna seja feita de transferências, isto já legitimou os questionamentos da dominação europeia. O trabalho de Cheikh Anta Diop sobre o Egito negro (Nations nègres et culture, 1954) - [Nações negras e cultura], reforçado pelas hipóteses de Black Athena (Atena negra) por Martin Bernal, visava essencialmente a designar, no início da descolonização, uma herança africana arcaica no cerne da civilização europeia. A questão das transferências culturais pode então incluir uma parte das abordagens pós-coloniais. Mas ela não se reduziria a isso. Quando um historiador medievalista destaca o fato de que a mística alemã encarnada pelo Mestre Eckhart tomou emprestado sua teoria do intelecto de Averroès (FLASCH, 2008), e que o desvio da filosofia grega pelo pensamento islâmico tornou-se um objeto clássico dos estudos gregos (BÜTTGEN, 2009), não se trata de uma questão de pós-colonialismo, mas da circulação de sistemas conceituais que, dependendo do contexto receptor, modifica sua significação. ${ }^{10}$

A historiografia das transferências culturais relativiza especialmente a noção de centro. É claro que a história, assim que excede os limites da nação ou área cultural da qual emana, para integrar círculos concêntricos maiores, considera que as referências próprias à sua área cultural de pertencimento são centrais. Quando histórias universais começam a ser escritas na Universidade de Göttingen, no último terço do século XVIII (MARINO, 1995; BÖDEKER, BÜTTGEN, ESPAGNE, 2010), e que a Arábia, a Índia ou a China são integradas nessa varredura global da história humana, consideramos que a Europa está no centro, e que entrando na história, as culturas periféricas se integram em um conjunto cujo centro está claramente determinado: europeu. Não podemos deixar de pensar que a "história global" é ela mesma estruturada a partir de um centro anglo-saxão. Outros centros existiram ao longo da história. Pensemos no Império do Meio e a exigência dos imperadores chineses em matéria de cartografia: que a China fosse representada no centro dos mapas do mundo conhecido. Pensemos sobre os hábitos da Turquia kemalista de desenhar mapas do mundo colocando no centro a Anatólia, ela mesma no centro de um mundo turco equidistante de um lado da costa da Argélia e, de outro, da costa da Ásia central (COPEAUX, 2000). O questionamento dos centros é uma parte fundamental da pesquisa sobre as transferências culturais.

A relatividade radical do centro resulta em fazer coincidir o global e o particular, cada particularidade devendo ser creditada ao seu próprio acesso ao global. Há lugares onde essa

\footnotetext{
${ }^{10}$ As explicações platônicas utilizadas por Garcilaso de la Vega para descrever sua cultura original resulta em uma dupla projeção: a das categorias platônicas sobre a história do povo Inca, e a dos exemplos Incas para reforçar um modelo platônico. Veja: Carmen Bernand, Un Inca platonicien, Garcilaso de la Vega. Paris: Fayard, 2010.
} 


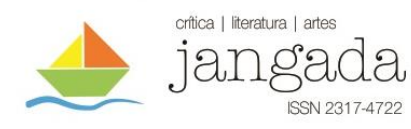

coincidência é facilitada: centros urbanos, universidades, bibliotecas, que podem ser considerados "portais sobre a globalidade". Estudar estes lugares (que iremos nos abster de fornecer uma lista exaustiva) é, obviamente, uma tarefa importante na pesquisa sobre as transferências. Pode-se pensar em um lugar como a biblioteca de Göttingen, principal biblioteca dos países germânicos e primeiro centro a coletar, desde meados do século XVIII, toda a literatura científica de língua francesa, inglesa, italiana, russa ou alemã, para alimentar um ensino que se pretendia uma ciência universal do homem. De maneira bem diferente, pode-se pensar em cidades onde encontramos um grande número de grupos étnicos, tais como Vilnius/Wilna/Wilno, cidade judia, alemã, polonesa, lituana, karaita e russa ao mesmo tempo, lugar de disseminação da cultura judaica e local do surgimento de uma literatura nacional polonesa e, depois, lituana. Esses "portais sobre a globalidade" associam as transferências culturais à categoria de lugar.

Um transferência cultural é, às vezes, uma tradução. Basta olhar uma edição de um romance em uma língua qualquer e sua tradução em uma outra língua, observar o discursos de acompanhamento das quartas capas, as ilustrações, os formatos, o efeito do contexto das séries e até mesmo a tipografia, para ver que uma tradução não é de forma alguma um equivalente. Ela o é menos ainda quando não se declara como tal, mas simplesmente inspirada por um original, à maneira de alguns autores latinos, que se inspiraram nos originais gregos. Lucrécia não é certamente um equivalente para Demócrito. Tradução evidencia o fato de que os conceitos estão enraizados em contextos semânticos e que o deslocamento do contexto semântico relacionado à tradução representa uma nova construção de sentido. Mas a tradução é também um objeto de pesquisa concernente à sociologia histórica ou à história do livro, as quais apoiamse naturalmente em pesquisas relacionadas às transferências culturais. O estudo prosopográfico dos tradutores leva a pensar sobre os modos de aquisição das línguas, sobre os critérios a partir dos quais opera-se a escolha dos livros a serem traduzidos. É importante analisar a estratégia das editoras, seu modo de funcionamento, o eco encontrado pelas obras traduzidas. Da tradução das Septante $^{11}$ às primeiras traduções de Kant, no século XIX, que cruzaram com grande dificuldade de abordagem para o texto em alemão, a hermética versão latina de Friedrich Gottlieb Born e a versão italiana de Vincenzo Mantovani, a análise não linguística do fenômeno das traduções é uma das linhas da pesquisa sobre as transferências culturais.

${ }^{11}$ Ou Septuaginta; tradução em etapas da Bíblia hebraica para o grego koiné. - (Nota do tradutor) 
Esta pesquisa fornece um acesso à compreensão, se não da história geral, ao menos de configurações transnacionais amplas, articulando a descrição do particular e do universal. A globalidade deve, de fato, ser observada a partir de um caso bastante preciso, até mesmo por singularidades. A acribia do filólogo ou do geneticista observando a sucessão de dois estratos textuais, de duas variantes, acompanha e corrige a reflexão sobre a circunavegação dos conceitos. Nenhum planisfério pode fazer economia no desenho dos rios e costas. É da pluralidade das línguas que se pode deduzir os deslocamentos semânticos das traduções. Mais uma teoria em andamento que um ensaio de doutrina, a pesquisa sobre as transferências culturais poderia levar a um novo ponto de vista sobre as ciências humanas e sociais.

\section{REFERÊNCIAS BIBLIOGRÁFICAS}

AMSELLE, Jean-Loup. Branchements. Anthropologie de l'universalité des cultures. Paris: Flammarion, 2001.

BERNAND, Carmen. Un Inca platonicien. Garcilaso de la Vega. Paris: Fayard, 2005.

BÖDEKER, Hans-Erich; BÜTTGEN, Philippe; ESPAGNE, Michel (éd.). Göttingen vers 1800. L'Europe des sciences de l'homme. Paris: Le Cerf, 2010.

BÜTTGEN, Philippe; LIBERA, Alain de; RASCHED, Marwan; ROSIER-CATACH, Irène (éd.). Les Grecs, les Arabes et nous. Enquête sur l'islamophobie savante. Paris: Fayard, 2009. COPEAUX, Étienne. Une vision turque du monde à travers les cartes de 1931 à nos jours. Paris: CNRS Éditions, 2000.

ESPAGNE, Michel; WERNER, Michael. (Textos reunidos e apresentados por). Transferts. Les relations interculturelles dans l'espace franco-allemand $\left(X V I I I^{e}-X I X^{e}\right)$. Paris : Éditions recherche sur les Civilisations, 1988.

ESPAGNE, Michel. Les Transferts culturels franco-allemands. Paris: PUF, 1999.

FLASCH, Kurt. D’Averroès à Maître Eckhart, Les sources arabes de la "mystique » allemande. Paris: Vrin, 2008.

JUSTI, Carl. Velazquez und sein Jahrhundert. Bonn: Cohen, 1903.

MARINO, Luigi. Praeceptores Germaniae: Göttingen 1770-1820. Göttingen: Vandenhoeck \& Ruprecht, 1995

SPRINGER, Anton. Bilder aus der neueren Kunstgeschichte. Bonn: A. Marcus, 1867.

WÖLFFLIN, Heinrich. Kunstgeschichtliche Grundbegriffe. Munich: Bruckmann, 1915. 


\section{Para citar este artigo}

Referência eletrônica:

Michel Espagne, «La notion de transfert culturel », Revue Sciences/Lettres [En ligne], 1 | 2013, mis en ligne le 18 avril 2013, consulté le 22 avril 2015. URL : http://rsl.revues.org/219 ; DOI : $10.4000 /$ rsl.219

\section{Autor}

\section{Michel Spain}

Diretor de pesquisa CNRS, Diretor do L'UMR 8547 Pays germaniques : transferts culturels/archives Husserl. Responsable de l'équipe "Transferts culturels"

Entre as publicações: Les Transferts culturels franco-allemands, Paris, PUF, 1999.L'Histoire de l'art comme transfert culturel, Paris, Belin, 2009. Avec Michael Werner (textes réunis et présentés par), Transferts. Les relations interculturelles dans l'espace franco-allemand (XVIII ${ }^{e}$-XIX ${ }^{e}$ siècles), Paris, Éditions Recherche sur les Civilisations, 1988. Avec Hans-Erich Bödeker et Philippe Büttgen (éd.), Göttingen vers 1800. L'Europe des sciences de l'homme, Paris, Le Cerf, 2010.ompleto]

Publicado na Revue Sciences/Lettres, 1 | 2013

\section{Direitos autorais}

(C) Revue Sciences/Lettres

\section{Tradução}

Dirceu Magri 